\title{
Short-term Effect of Fine Particulate Matter on Children's Hospital Admissions and Emergency Department Visits for Asthma: A Systematic Review and Meta-analysis
}

\author{
Hyungryul Lim ', Ho-Jang Kwon', Ji-Ae Lim', Jong Hyuk Choi', Mina Ha', Seung-sik Hwang ${ }^{2}$, Won-Jun Choi ${ }^{3}$ \\ ${ }^{1}$ Department of Preventive Medicine, Dankook University College of Medicine, Cheonan; ${ }^{2}$ Department of Social and Preventive Medicine, Inha \\ University School of Medicine, Incheon; ${ }^{3}$ Department of Occupational and Environmental Medicine, Gachon University Gil Medical Center, \\ Incheon, Korea
}

Objectives: No children-specified review and meta-analysis paper about the short-term effect of fine particulate matter $\left(\mathrm{PM}_{2.5}\right)$ on hospital admissions and emergency department visits for asthma has been published. We calculated more precise pooled effect estimates on this topic and evaluated the variation in effect size according to the differences in study characteristics not considered in previous studies.

Methods: Two authors each independently searched PubMed and EMBASE for relevant studies in March, 2016. We conducted random effect meta-analyses and mixed-effect meta-regression analyses using retrieved summary effect estimates and $95 \%$ confidence intervals ( $\mathrm{Cls}$ ) and some characteristics of selected studies. The Egger's test and funnel plot were used to check publication bias. All analyses were done using $\mathrm{R}$ version 3.1.3.

Results: We ultimately retrieved 26 time-series and case-crossover design studies about the short-term effect of PM 2.5 on children's hospital admissions and emergency department visits for asthma. In the primary meta-analysis, children's hospital admissions and emergency department visits for asthma were positively associated with a short-term $10 \mu \mathrm{g} / \mathrm{m}^{3}$ increase in $\mathrm{PM}_{2.5}$ (relative risk, 1.048; $95 \% \mathrm{Cl}, 1.028$ to $\left.1.067 ; \mathrm{I}^{2}=95.7 \%\right)$. We also found different effect coefficients by region; the value in Asia was estimated to be lower than in North America or Europe.

Conclusions: We strengthened the evidence on the short-term effect of $\mathrm{PM}_{2.5}$ on children's hospital admissions and emergency department visits for asthma. Further studies from other regions outside North America and Europe regions are needed for more generalizable evidence.

Key words: Particulate matter, Asthma, Child, Review, Meta-analysis, Hospitalization

\section{INTRODUCTION}

Received: April 7, 2016 Accepted: July 14, 2016

Corresponding author: Ho-Jang Kwon, MD, PhD

119 Dandae-ro, Dongnam-gu, Cheonan 31116, Korea

Tel: +82-41-550-3879, Fax: +82-41-556-6461

E-mail: hojang@dankook.ac.kr

This is an Open Access article distributed under the terms of the Creative Commons Attribution Non-Commercial License (http://creativecommons.org/licenses/by$\mathrm{nc} / 4.0 / /$ which permits unrestricted non-commercial use, distribution, and reproduction in any medium, provided the original work is properly cited.
The adverse health effects of air pollution on respiratory and cardiovascular diseases are well known to the public. Regulation and monitoring of air pollution are performed at both the national and international levels. Particulate matter (PM) is one type of air pollutant. It is not a specific chemical entity, unlike other commonly known pollutants such as ozone, sulphur dioxide, and nitrogen dioxide. It is a physical category of 
dust with different components mixed together [1]. The particle size determines the different categorizations: $\mathrm{PM}_{10}$ (less than $10 \mu \mathrm{m}$ aerodynamic diameter) and PM $_{2.5}$ (less than 2.5 $\mu \mathrm{m}$ aerodynamic diameter). $\mathrm{PM}_{2.5}$ is also known as fine $\mathrm{PM}$.

$\mathrm{PM}_{2.5}$ has been reported to play a major role in increasing the chance of mortality due to cardiovascular diseases because it can penetrate the capillary vessel of the lungs and reach the alveoli $[2,3]$. Extensive research has been conducted on the association between $\mathrm{PM}_{2.5}$ and respiratory diseases including asthma. Asthma is a syndrome in which reversible respiratory obstruction occurs and is characterized by hypersensitiveness to allergens. When stimulated, a person experiences wheezing and dyspnea. In most cases, asthma is caused by a genetic predisposition and is triggered by environmental allergens.

The prevalence rate of asthma is high in children. In the case of South Korea (hererafter Korea), the prevalence rate of asthma in children steadily increased due to urbanization and westernization. In 2010, a national study based on the International Study of Asthma and Allergies in Childhood questionnaire found that $10.1 \%$ of elementary school students and $8.5 \%$ of middle school students had experienced symptoms of asthma in the past 12 months [4]. These numbers should not be ignored.

Recently published systematic reviews and meta-analyses reported the pooled relative risk (RR) of the number of hospital admissions and emergency department (ED) visits due to asthma as 1.023 (95\% confidence interval [Cl], 1.015 to 1.031 , per $10 \mu \mathrm{g} / \mathrm{m}^{3}$ increase) when examining the effects of $\mathrm{PM}_{2.5}$ on the total population, and $1.025(95 \% \mathrm{Cl}, 1.013$ to 1.037 , per 10 $\mu \mathrm{g} / \mathrm{m}^{3}$ increase) when the subject was confined to children only [5]. Another review that examined the effects of $\mathrm{PM}_{2.5}$ on ED visits due to asthma reported a pooled RR of $1.036(95 \% \mathrm{Cl}$, 1.018 to 1.053 , per $10 \mu \mathrm{g} / \mathrm{m}^{3}$ increase) [6]. However, existing studies contain several limitations. These studies were not focused on childhood asthma and only presented pooled effect estimates in children as subgroup analysis. Moreover, most of the relevant studies were conducted in North America and Europe [7-28], and although studies conducted in other regions exist [29-32], they did not consider the varying effects of $\mathrm{PM}_{2.5}$ according to different regions. The design of the study, the background $\mathrm{PM}_{2.5}$ mean concentration and variation of the region where the study was conducted, and the time of study may change the effects as well, but these factors were not adequately considered in existing studies.
In addition to the two reviews mentioned above, seven new relevant papers have recently been published [22-28]. Of these, the time-series studies assessed the exposure to air pollution by using the exposure value of the population-weighted average in between the measuring points of air pollution $[22,24,27]$, and the case-crossover design studies used the method of matching individual addresses with the $\mathrm{PM}_{2.5}$ measures $[25,26]$, which yielded more accurate results. Therefore, by including these recent developments, we tried to calculate more accurate pooled effect estimates of the effects of $\mathrm{PM}_{2.5}$ on childhood asthma and assess the variations of effects induced by differences in some factors such as region or date of research, which have been not adequately examined yet.

\section{METHODS}

\section{Selection Criteria}

We first determined some criteria for selecting relevant studies. They are as follows:

1) The subject of study was limited to children and adolescents under the age of 20 .

2) Study results were limited to computerized records of hospital admissions and ED visits. Outpatient visits were excluded. Hospital admissions confirmed through interviews were not eligible. Subjective symptoms, decrease in pulmonary function, and use of emergency inhalers were not considered endpoints.

3) Effect estimates had to be presented as an odds ratio (OR) or RR.

\section{Search Terms and Study Selection}

When deciding on search terms, we minimized keywords in order to increase the sensitivity of our searches. Some of the search terms we used were child*, pediatric*, fine particulate matter*, fine particle*, $\mathrm{PM}_{2.5}$, asthma*, hospitalization, hospitalisation, admission*, ed, er, and emergency. We searched studies to include in our meta-analysis using PubMed and EMBASE in March of 2016. Moreover, we selected the final eligible studies after having two authors each independently select references according to the criteria above and the same search terms and then comparing the two lists.

\section{Statistical Methods}

The effect size was expressed as RR. We considered the OR as a proxy to the RR. In order to have all the effect estimates 
chosen from the selected studies to reflect the same $10 \mu \mathrm{g} / \mathrm{m}^{3}$ increment of $\mathrm{PM}_{2.5}$ concentration, we implemented metaanalyses after recalculating the $\beta$ coefficient and $95 \% \mathrm{Cl}$ presented in each study. Because the purpose of this study is to combine and identify the effects from regions all over the world, generalization of heterogeneous parts of the research group was its goal. Therefore, the random effects model using the DerSimonian and Laird [33] estimation method was mainly considered, rather than the fixed effects model [33,34]. When estimating the pooled effect, the model takes into account both the between-study variation and the within-study variation and provides a greater confidence level than the fixed effects model. The l-squared value (\%) was calculated in order to identify heterogeneity.

In the primary meta-analysis of this study, an effect estimate that could represent the selected studies was used. We used the same lag value that was presented in the original paper [35], but if a study presented multiple estimates from different lags, we selected the one with the largest effect size. This is because, generally, these works report the greatest effect size [36]. If a study did not have one effect estimate that could represent the research, we selected two or more values that were obtained from subjects that were mutually exclusive (that is, if a study did not present an effect estimate in whole participants but presented two or more separate values from stratified groups, we included those in the meta-analysis). In order to identify publication bias, we conducted the Egger's test and identified the degree of asymmetry through a funnel plot [37].

Moreover, we conducted category-specific meta-analyses in order to determine what factors influenced the effect of $\mathrm{PM}_{2.5}$, if those influences were robust, and what factors contributed to the heterogeneity of effect estimates. We conducted the analyses by sorting the effect estimates into categories of age, results (records of hospital admissions or ED visits), season, design of the study, region, and the lag of exposure. We also conducted a separate analysis according to whether or not different pollutants were adjusted in the statistical model.

We hypothesized that the components of $\mathrm{PM}_{2.5}$ would change according to the time of the study and that the size of the effect could change according to the components. In addition, we thought that the variation and the mean concentration of $\mathrm{PM}_{2.5}$ in the region where the study was conducted might change the size of the effect. Therefore, through mixedeffects meta-regression, we derived an effect estimate of the time of the study, and the mean and standard deviation of the concentration in the study region on RR for childhood asthma.

All statistical analyses performed using $R$ version 3.1.3 (Comprehensive R Archive Network: http://cran.r-project.org) and we carried out a series of statistical analyses described above through the meta package. All statistical analyses set a 5\% significance level for the two-tailed test.

\section{RESULTS}

\section{Selection of Relevant Studies and Extracting Effect Estimates and Their Confidence Intervals}

A total of 661 references were searched using the search terms mentioned above, and of those, we first selected 56 to examine in whole by excluding overlapping studies $(n=171)$ and reading the titles and abstracts $(n=490)$. Then we ultimately selected 26 studies according to the selection criteria and extracted effect estimates (Figure 1). The 26 studies were published between 1999 and 2016, and we summarized each of the research outlines and the main research results in Table 1. Most of the research was conducted in North America and Europe and both time-series and case-crossover designs were almost equally represented.

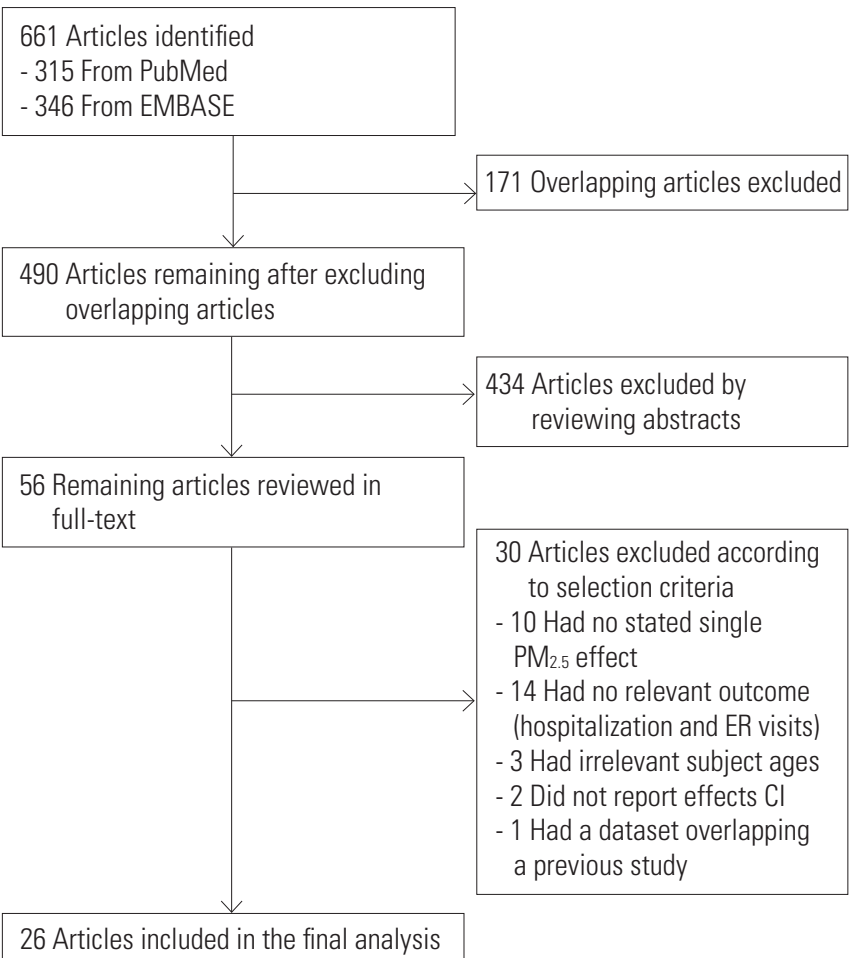

Figure 1. Selection process for systematic review and metaanalysis. $\mathrm{PM}_{2.5}$, fine particulate matter; ER, emergency room; $\mathrm{Cl}$, confidence interval. 


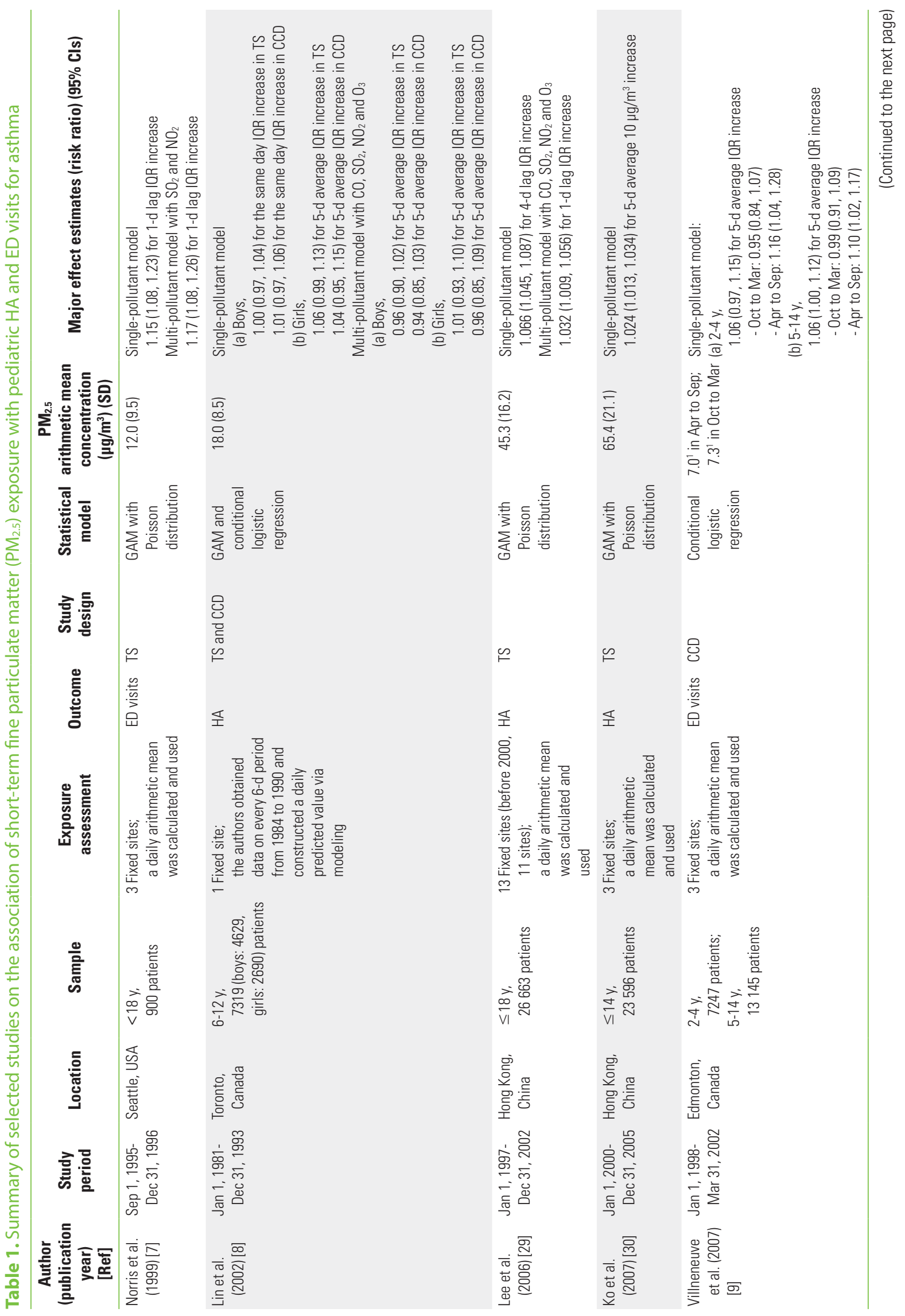



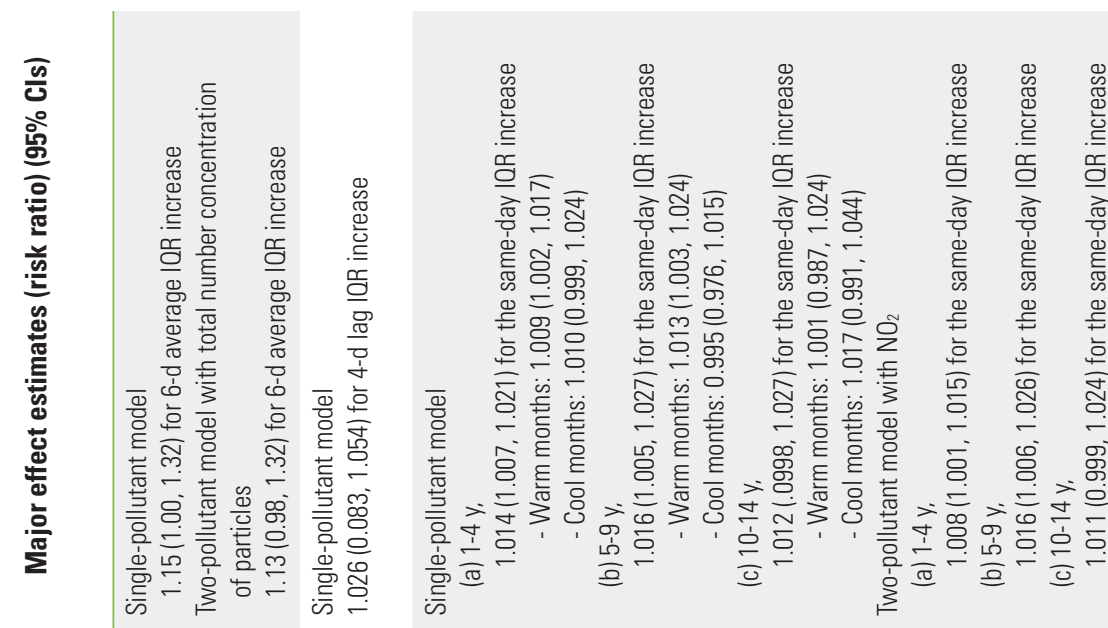

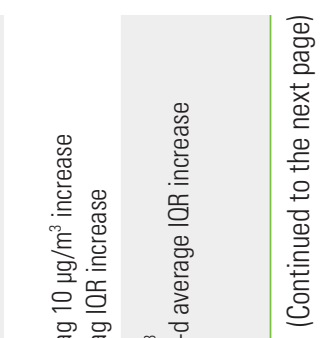

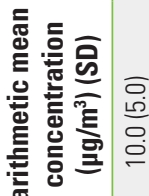

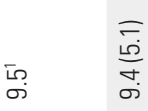

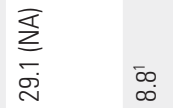

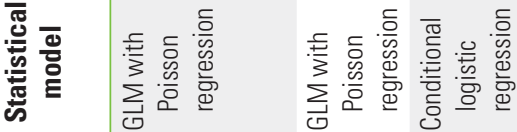

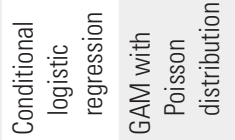

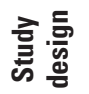

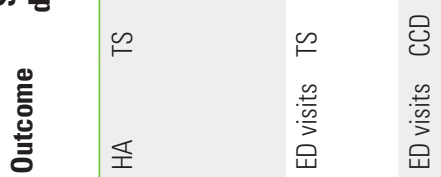

岂

조문

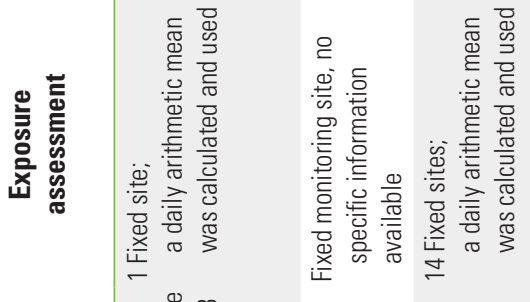

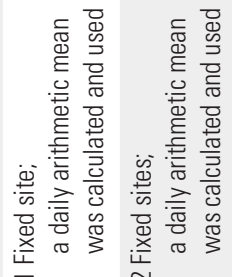

을 $\infty$

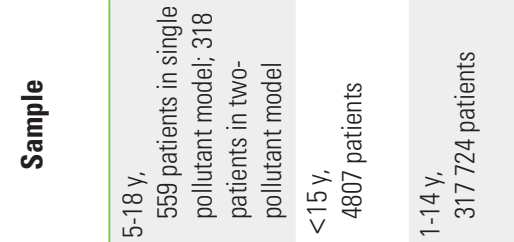

है के

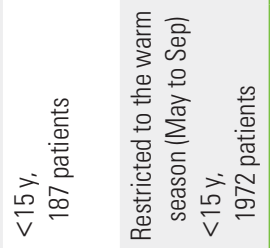

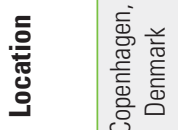

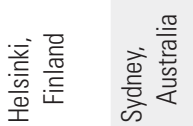

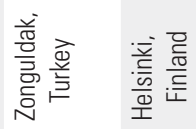

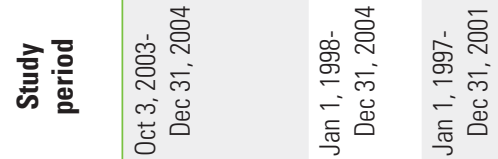

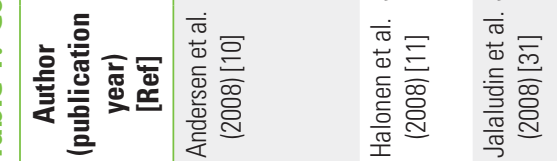

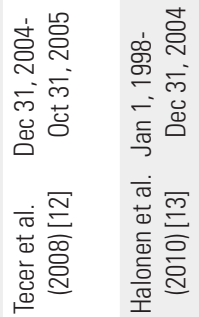




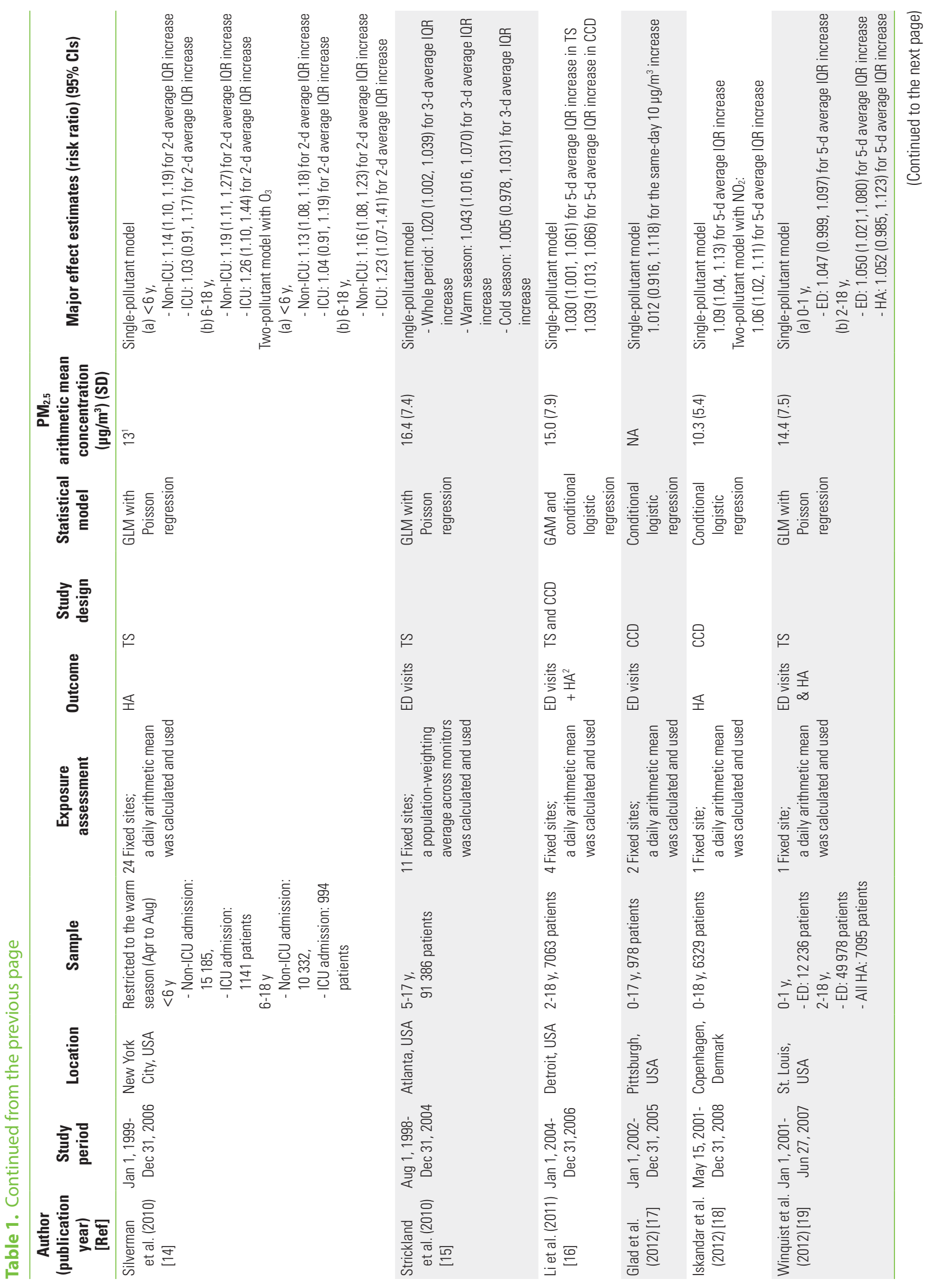




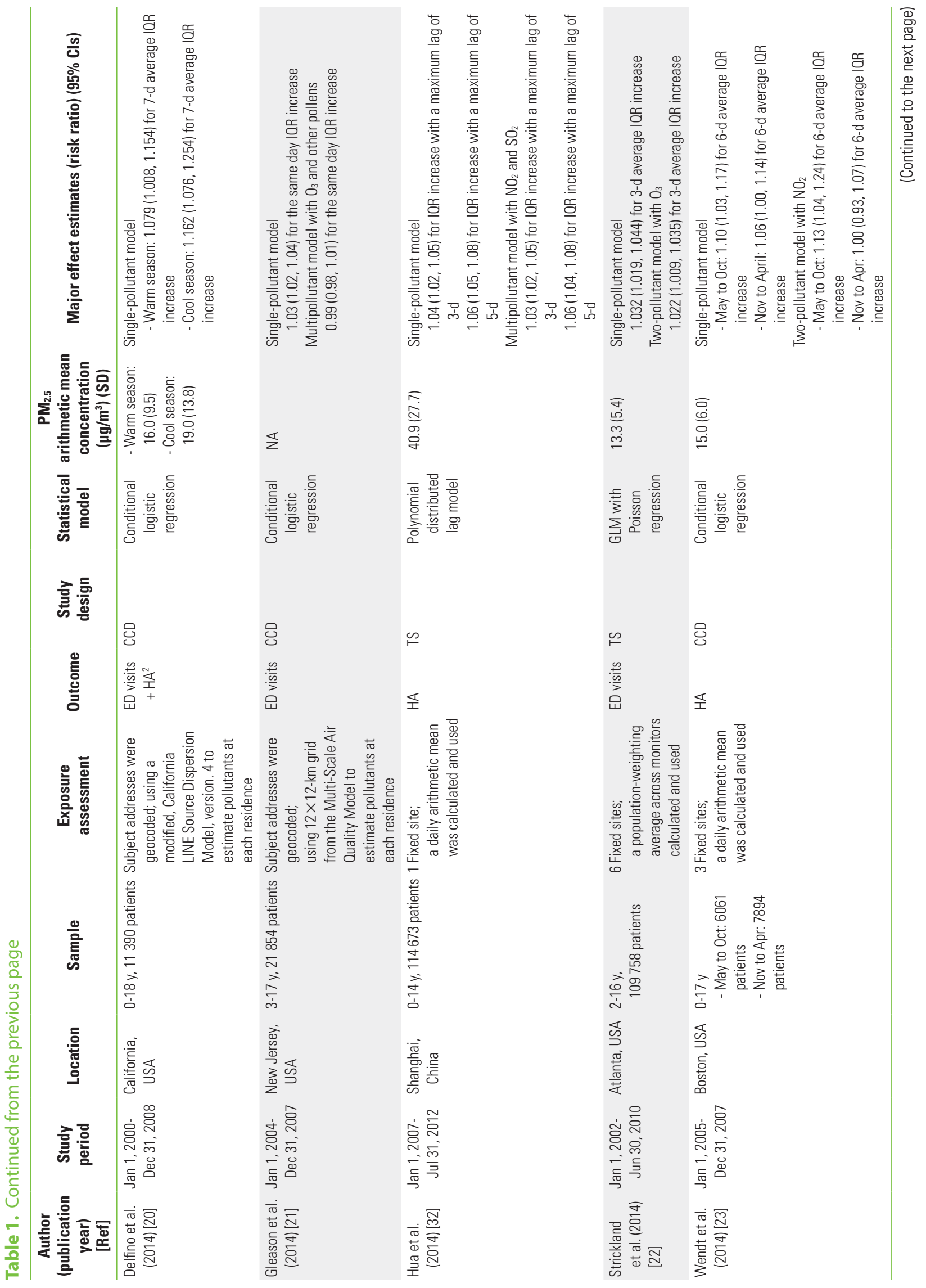



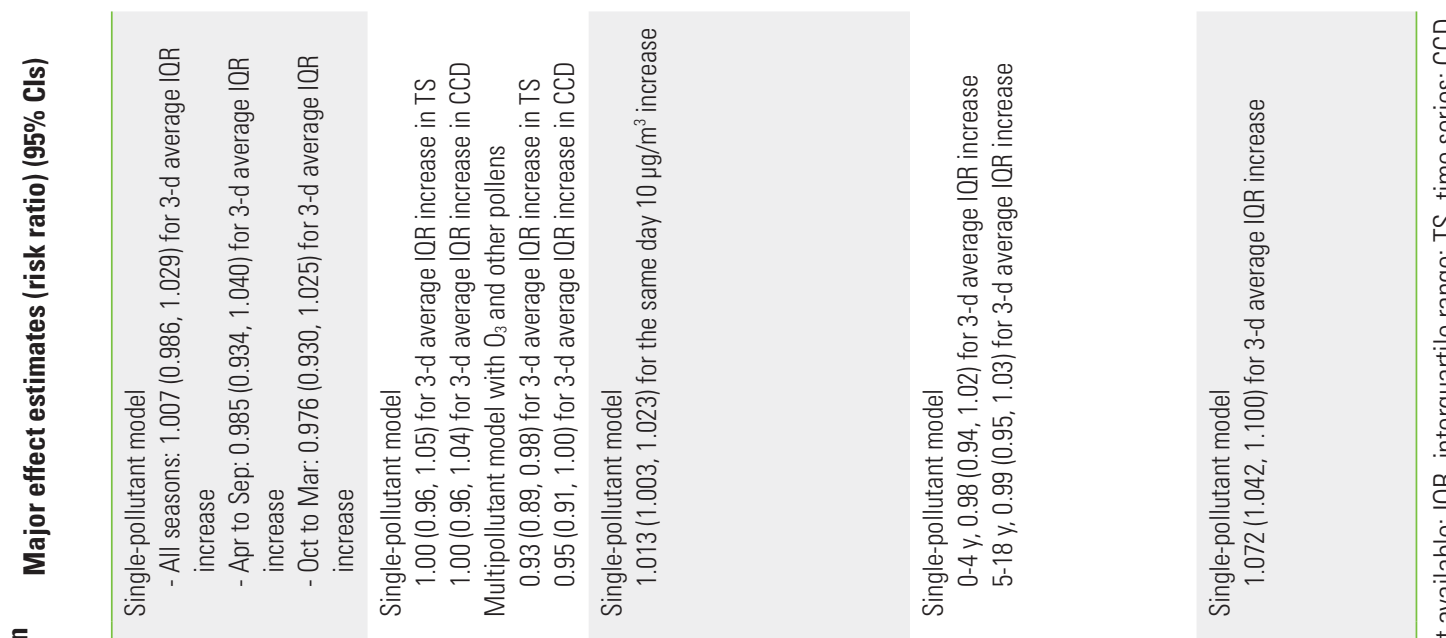

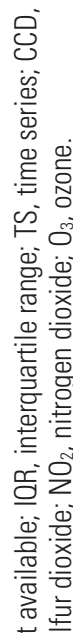
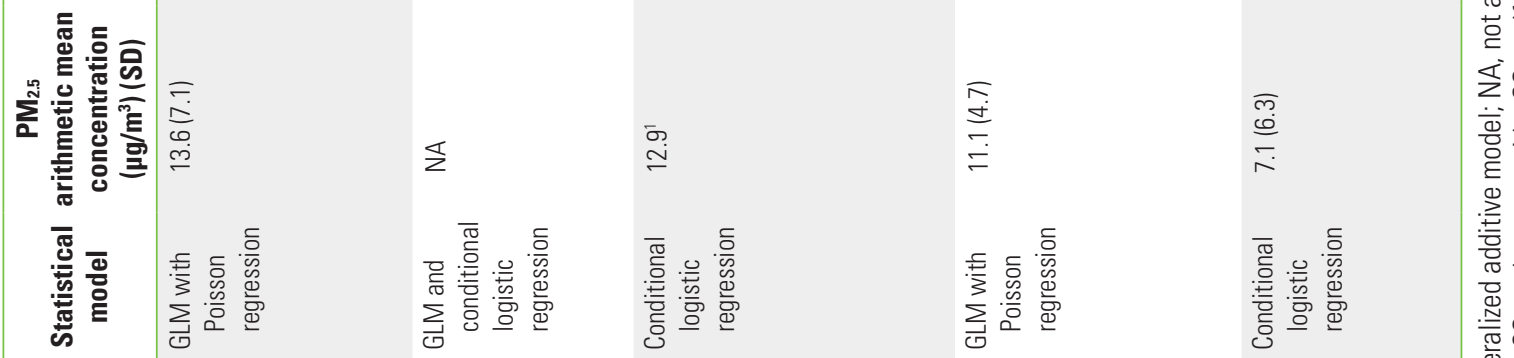

है

这 के

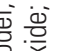

吾

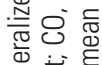

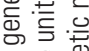
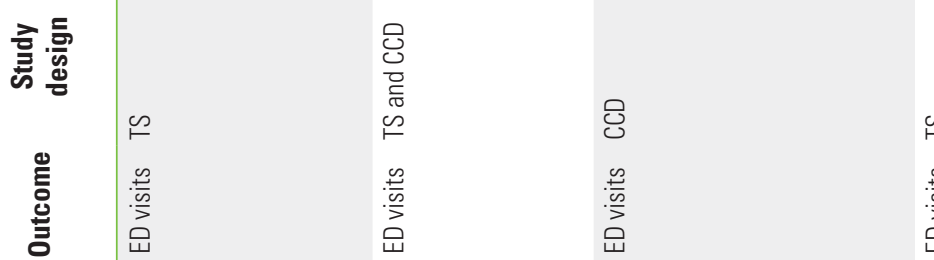

这嵌

产
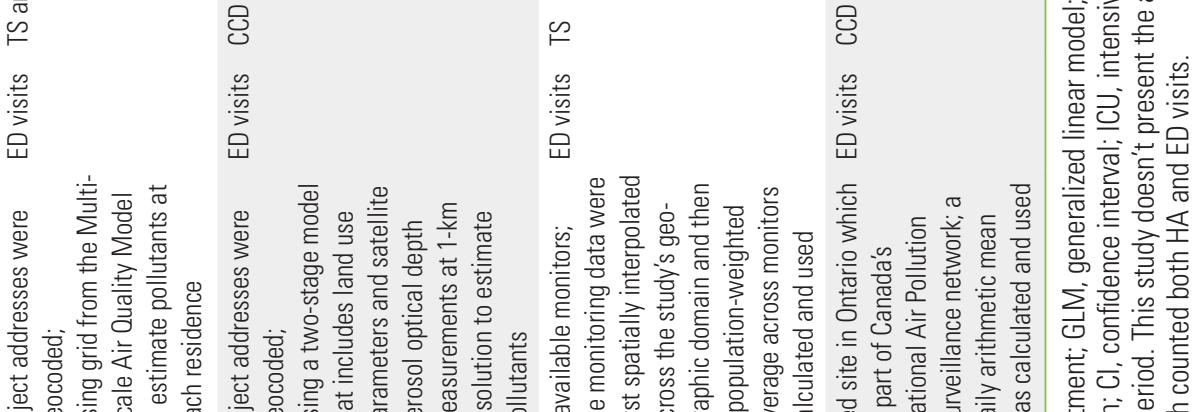

प1

过范荡要

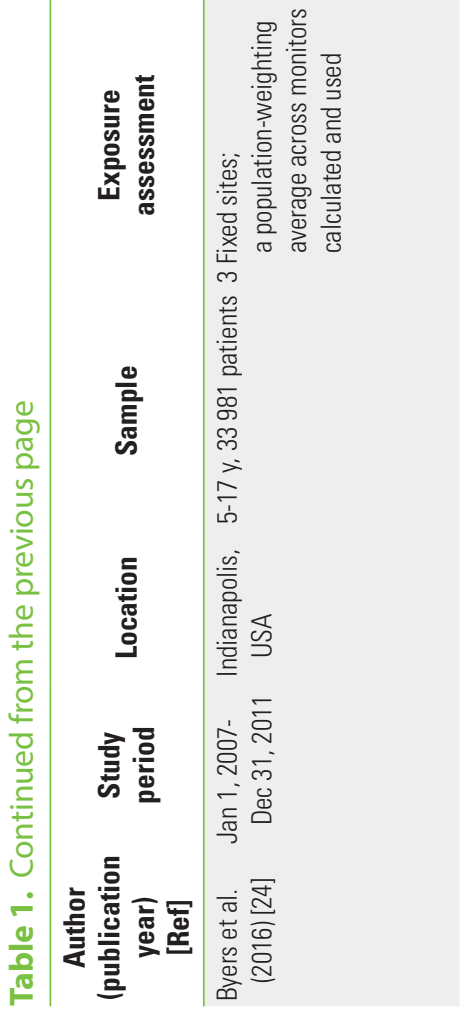

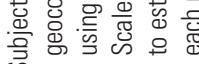
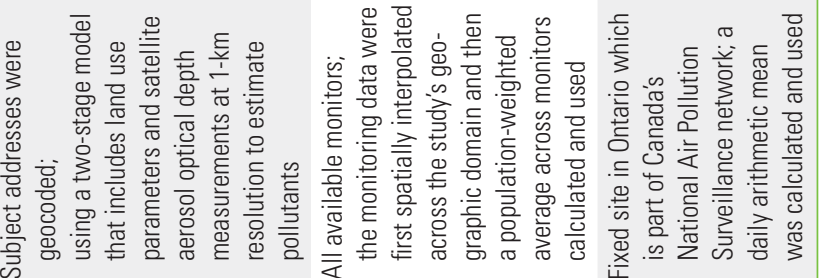

밍.

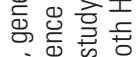

$\sum$ 은

氙它犃

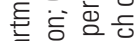
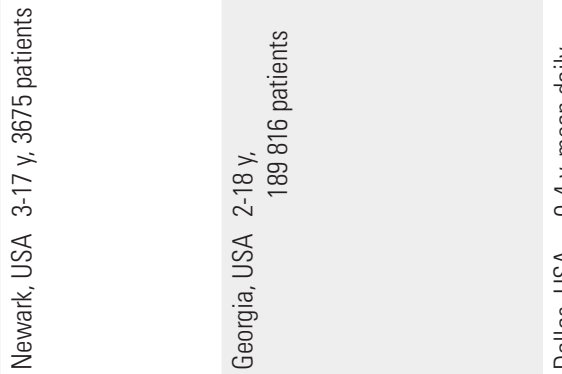

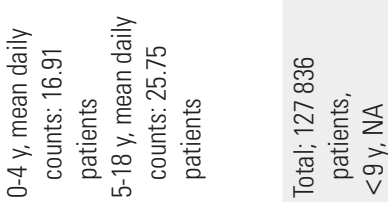

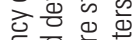

흥 흉 产

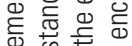

它的踥

혛ㅎㅎ응

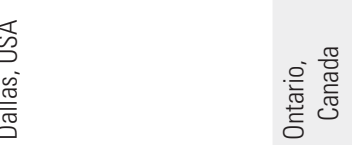

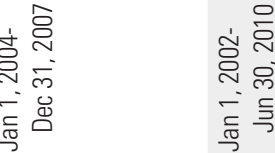

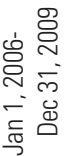

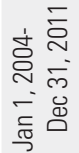

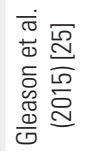

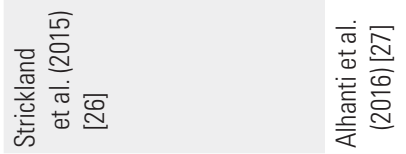

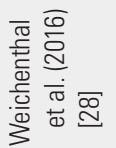

.

등 흘 흔

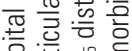

के

i

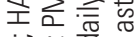

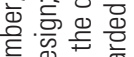

空

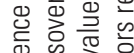

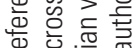

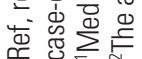


After extracting all effect estimates and $\mathrm{Cls}$ from the main body of each research paper and its supplementary materials, we broke it down to a total of 244 effect estimates. Of those, we selected 33 representative effect estimates from each study to use in our primary meta-analysis.

\section{Primary Meta-analysis}

In the random effects model, we were able to find that when the concentration of $\mathrm{PM}_{2.5}$ increased by $10 \mu \mathrm{g} / \mathrm{m}^{3}$, the risk of a child's hospital admission or ED visit increased by $4.8 \%$ (RR, $1.048 ; 95 \% \mathrm{Cl}, 1.028$ to 1.067). The I-squared value, which shows the heterogeneity of the included studies, was $95.6 \%$, a high figure. We presented a forest plot for the included effect estimates and pooled estimates (Figure 2).

\section{Publication Bias}

To schematically examine the tendency toward publication bias, we found a relatively symmetrical shape in the funnel plot and confirmed that there was not much of a bias because there was not statistically significant $(p=0.42)$ in the Egger's test (Figure 3).

\section{Category-specific Meta-analyses}

We found that the effects are greater on children below the age of five than on children ages 5 to 19, in warmer seasons,

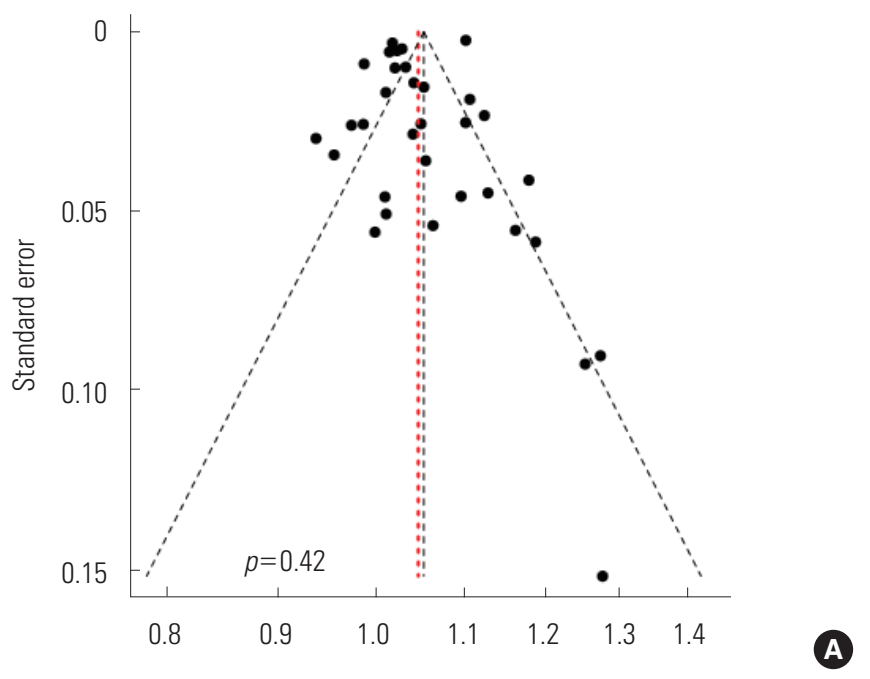

Risk ratio and in North America and Europe than in Asia. The pooled effect estimates extracted through the multi-pollutant model was also statistically significant (RR, 1.040; $95 \% \mathrm{Cl}, 1.022$ to 1.057). According to the lags, the effect changed greatly from

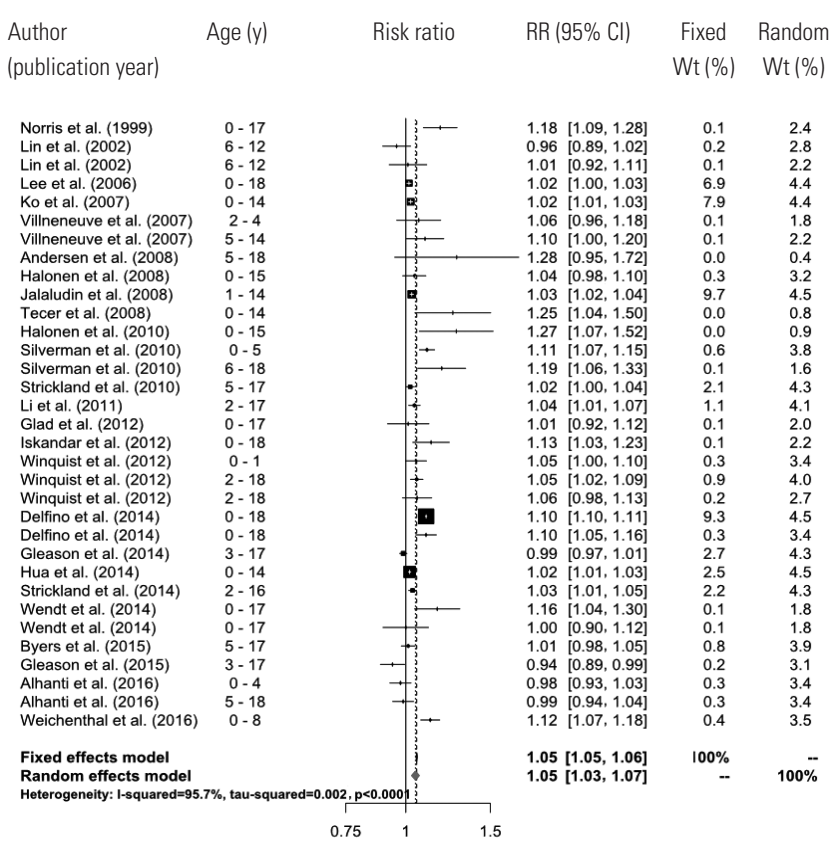

Figure 2. Forest plot for selected effect estimates in primary meta-analysis. $\mathrm{RR}$, relative risk; $\mathrm{Cl}$, confidence interval; $\mathrm{Wt}$, weight.

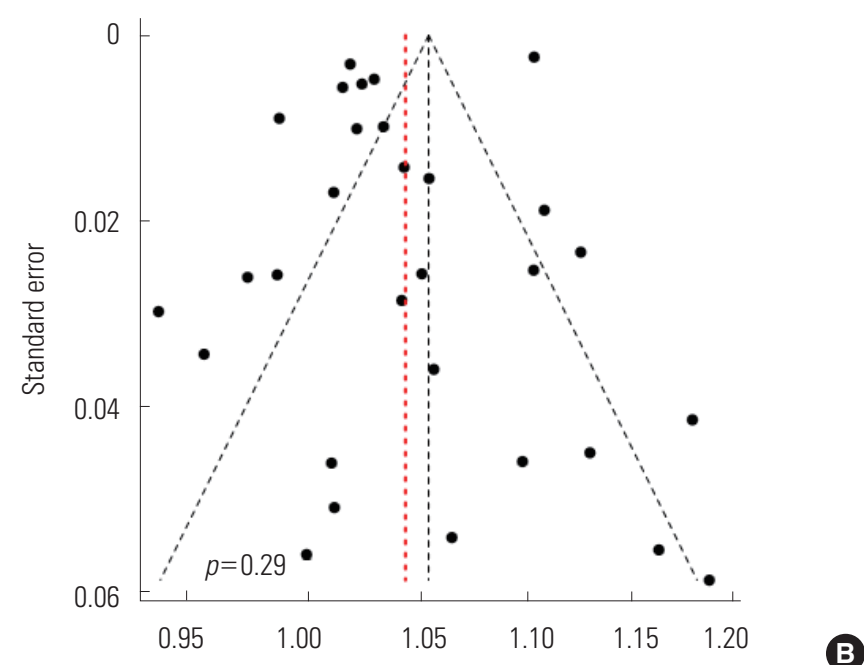

Risk ratio

Figure 3. Funnel plot for a possible selection bias in the primary meta-analysis (A). After removing three estimates (Anderson et al. [8], Tecer et al. [12], and Halonen et al. [13]) from the right-lower area in A, still symmetrical shape is shown (B). Each black circle denotes each effect estimate of the selected studies, and the vertical red dotted line denotes the pooled random effect risk ratio in the primary meta-analysis. The $p$-value is derived from Egger's test. 
Table 2. Results of category-specific meta-analyses

\begin{tabular}{|c|c|c|c|}
\hline & $\begin{array}{c}\text { No. of study } \\
\text { (no. of estimate) }\end{array}$ & RR $(95 \% \text { Cls })^{1}$ & $I^{2}(\%)$ \\
\hline \multicolumn{4}{|l|}{$\mathrm{Age}^{2}$} \\
\hline$<5$ & $7(9)$ & $1.044(1.017,1.071)$ & 81.9 \\
\hline $5-18$ & $12(15)$ & $1.027(1.011,1.043)$ & 76.8 \\
\hline \multicolumn{4}{|l|}{ Outcome } \\
\hline $\mathrm{HA}$ & $10(15)$ & $1.048(1.029,1.067)$ & 77.7 \\
\hline ED visits & $15(17)$ & $1.027(1.011,1.044)$ & 79.5 \\
\hline \multicolumn{4}{|l|}{ Season } \\
\hline Cold & $7(8)$ & $1.015(0.994,1.037)$ & 57.1 \\
\hline Warm & $9(11)$ & $1.085(1.051,1.119)$ & 94.8 \\
\hline \multicolumn{4}{|l|}{ Study design } \\
\hline TS & $15(19)$ & $1.028(1.015,1.041)$ & 76.9 \\
\hline CCD & $13(17)$ & $1.051(1.020,1.084)$ & 96.6 \\
\hline \multicolumn{4}{|l|}{ Area } \\
\hline North America & $14(19)$ & $1.047(1.019,1.076)$ & 96.1 \\
\hline Europe & $8(11)$ & $1.075(1.030,1.123)$ & 65.9 \\
\hline China & $3(3)$ & $1.019(1.013,1.025)$ & 0.0 \\
\hline \multicolumn{4}{|c|}{ Multipollutant model } \\
\hline No & $25(33)$ & $1.054(1.037,1.071)$ & 96.0 \\
\hline Yes & $13(18)$ & $1.040(1.022,1.057)$ & 83.1 \\
\hline \multicolumn{4}{|l|}{ Time lag (d) } \\
\hline 0 (same day) & $12(14)$ & $1.018(1.005,1.028)$ & 60.9 \\
\hline 1 & $11(13)$ & $1.018(1.005,1.030)$ & 59.6 \\
\hline 2 & $8(8)$ & $1.002(0.984,1.021)$ & 84.6 \\
\hline 3 & $10(11)$ & $1.030(1.015,1.045)$ & 66.6 \\
\hline 4 & $4(4)$ & $1.016(0.969,1.065)$ & 83.1 \\
\hline 5 & $5(6)$ & $1.019(0.975,1.065)$ & 93.5 \\
\hline \multicolumn{4}{|l|}{ Average } \\
\hline 2 & $3(7)$ & $1.065(1.020,1.113)$ & 81.7 \\
\hline 3 & $11(15)$ & $1.019(1.006,1.033)$ & 82.2 \\
\hline 5 & $10(14)$ & $1.025(1.007,1.043)$ & 77.4 \\
\hline 6 & $3(5)$ & $1.029(0.938,1.129)$ & 69.9 \\
\hline
\end{tabular}

$\mathrm{RR}$, relative risk; $\mathrm{Cl}$, confidence interval; $\mathrm{HA}$, hospital admission; $\mathrm{ED}$, emergency department; TS, time-series; CCD, case-crossover design.

${ }^{1}$ Calculated by DerSimonian and Laird random effects model [33].

${ }^{2}$ There are two exceptions: Silverman et al. [14] and Iskandar et al. [18]: cutoff age is six.

$0.2 \%$ to $6.5 \%$, and the effect was large for 3-day lag and 3-day average lag (Table 2).

\section{Meta-regression Analyses}

We did not find a tendency toward change in the statistically significant RR according to the time of study and the standard deviation of the background concentration of the region of study. We found a negative tendency in the mean $\mathrm{PM}_{2.5}$ concentration by the region of study, but it was not statistical-

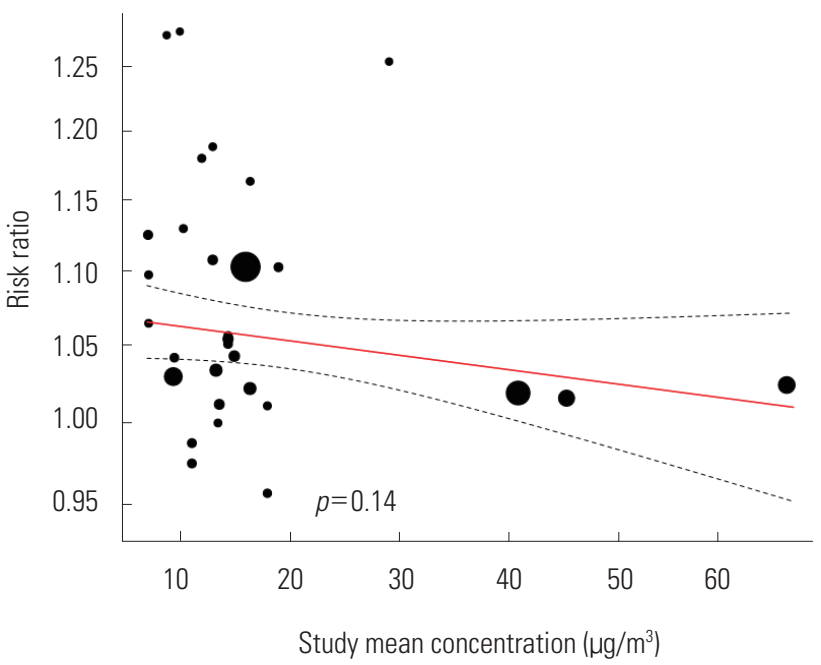

Figure 4. Bubble plot and regression line for mixed-effect meta-regression of study mean fine particulate matter $\left(\mathrm{PM}_{2.5}\right)$ concentration and effect estimate. The black circles denote each effect estimate and their sizes represent each weight. The bold red line indicates a linear relationship between study mean $\mathrm{PM}_{2.5}$ concentration and relative risk and the black dotted lines indicate a 95\% confidence interval.

ly significant $(\beta=-0.0008, p=0.14)$ (Figure 4).

\section{DISCUSSION}

In the primary meta-analysis of the effect estimates obtained from the 26 studies, we found that in the short-term, when the concentration of $\mathrm{PM}_{2.5}$ increased $10 \mu \mathrm{g} / \mathrm{m}^{3}$, the risk of a child's hospital admission or ED visit increased $4.8 \%$, which is statistically significant. The effect of $\mathrm{PM}_{2.5}$ could be considered quite robust, since the effect was maintained to 4.0\% even when we pooled the estimates extracted by the multi-pollutant model in this study. This number is greater than the $2.3 \%$ found among the total population presented in the aforementioned study of Zheng et al. [5]. These results show that children are more vulnerable to air pollution because their alveoli and airways are still growing, their immune systems are underdeveloped, and they spend more time outdoors, which increases ventilation [38].

Based on known biological mechanisms, the generation of reactive oxygen species (ROS) is accelerated because of the transition metal included in $\mathrm{PM}_{2.5}$. Oxidative stress from ROS may be related to epithelial cell destruction and allergic inflammation, and this process is known to be related to exacerbation of asthma [39]. Meanwhile, previous studies reported 
that arginase may participate in a process that fine particles exacerbate childhood asthma [40]. In vivo studies report that the overexpression of arginase influences the hyperresponsiveness of airways [41] and that fine particles exacerbate the airway's responsiveness in asthma in murine models [42]. Human epidemiological studies have shown that the variation of the ARG1 and ARG2 genes - which are related to the manifestation of arginase in childhood asthma patients-is statistically significant $[40,43]$.

In the preceding meta-analyses by Zheng et al. [5], they suggested 20 relevant studies on children's asthma. We found a discrepancy between the selected studies of Zheng et al. [5] and ours even aside from seven papers published more recently. They cited several studies that we excluded in the process of extracting eligible studies. On the other hand, the six studies included in this study were not cited by the preceding study. We selected studies and extracted results carefully focusing on children. Therefore, we believe that the 26 references selected for this study comprise the best selection.

We found that when the concentration of $\mathrm{PM}_{2.5}$ increased by $10 \mu \mathrm{g} / \mathrm{m}^{3}$, the risk of a child's hospital admission or ED visit increased by $4.8 \%$. This value is greater than the $2.5 \%$ increase in children found in the preceding meta-analysis by Zheng, et al. [5]. The following are some reasons to explain this difference. First, the newly added original studies included several studies in which the RR exceeded 1.10 when the measure of effect estimates was converted to $10 \mu \mathrm{g} / \mathrm{m}^{3}$ per increase $[7,9,13,20,23,28]$. Second, while the previous study pooled the effect estimates from the 0-day, 1-day, or 2-day average lags, we used the model with the greatest effect size out of the lags reported in the original studies.

In this study, we found a difference in RR according to the season, and during the warmer seasons, the RR was 1.085 $(95 \% \mathrm{Cl}, 1.051$ to 1.119$)$. The studies included in our metaanalysis showed quite consistent results $[9,20,22,23,31]$. We thought the reason for this was that during warmer seasons, children spend more time outdoors and therefore spend more time exposed to $\mathrm{PM}_{2.5 .}$. In addition, greater ventilation of buildings during these seasons makes it easier for air pollutants to penetrate inside the buildings. It was reported that the individual exposure concentration of $\mathrm{PM}_{2.5}$ that people living in well-ventilated environments showed high correlation to the concentration of the atmosphere [44]. The difference in components of $\mathrm{PM}_{2.5}$ according to the season may also be related, but because the extent of heterogeneity by region is too great, the evidence is not yet definitive [45-47].

In terms of the design of the studies, the pooled RRs for the time-series and the case-crossover design studies were 1.028 and 1.051, respectively. For the case-crossover design, the OR was calculated using the conditional logistic regression model. Compared to the RR, the OR has a tendency to overestimate the actual risk. However, it may be thought as a closer representation of reality than the exposure assessment of the timeseries because a recently published case-crossover study more accurately matched air pollutants using the addresses of individuals $[20,21,25,26]$. Residential information of patients entering hospitals or visiting the ED cannot be reflected in timeseries. If we suppose that $\mathrm{PM}_{2.5}$ having an influence on exacerbating asthma as true, even in one study region, there is a possibility that the large effect in certain area with a high concentration could be diluted because of smaller effects in other area with a low concentration. We think that the actual effect is somewhere between the RRs of the time-series studies and the ORs of the case-crossover studies.

When we examine the pooled RR of each lag, we can see that there is up to a $6 \%$ difference in value depending on the type of model. The effects of both the concentration three days before (3-day lag) and the average concentration over three days (3-day average lag) were considerable. This result is somewhat difficult to interpret. We need to consider the following factors when dealing with lags: that the ethnicities of the subject of study differ by regions and an accessibility to health services could change depending on the time of study. Through meta-regression analysis, we found a negative tendency among effect sizes depending on the mean concentration of $\mathrm{PM}_{2.5}$, but it was not statistically significant. Aside from the three studies in China which the mean concentrastion exceeded $30 \mu \mathrm{g} / \mathrm{m}^{3}$ (Figure 4), we did not find a negative tendency in the meta-regression analysis $(\beta=-0.0004, p=0.90)$. Therefore, we could not draw conclusions in this study regarding such a limited tendency. A negative tendency means that the effect on asthma is smaller for regions where the mean concentrations of $\mathrm{PM}_{2.5}$ are higher. This means that the relationship between the mean concentration and the childhood asthma could be non-linear, or more specifically, supra-linear.

When we examine the results according to region in the category-specific analyses, the pooled RR of the three studies conducted in Shanghai and Hong Kong was 1.019, which is a smaller value than those in North America (1.047) and Europe (1.075). This is similar to the results of the previous meta-anal- 
ysis that examined the short-term effects of $\mathrm{PM}_{2.5}$ on total mortality and cardiorespiratory mortality, and found that the pooled estimate in China was lower than in the US, Europe, Japan, and Australia [48]. A hypothesis that the components of $\mathrm{PM}_{2.5}$ in China are different from those of developed countries was raised regarding this finding. In other words, in China, the contributions of coal combustion and desert dust-rather than exhaust from automobiles-were greater than in other regions.

However, in a preceding meta-regression analysis including studies on $\mathrm{PM}_{10}$ and cardiorespiratory mortality conducted in China only, a statistically significant negative tendency was reported regarding the association between the mean concentrations of study regions and the effect sizes [49]. A study conducted across 27 US regions also reported that the effect of $\mathrm{PM}_{2.5}$ was greater in regions with lower background mean concentration, even though the result was not statistically significant [50]. In a cohort study on the effect of $\mathrm{PM}_{2.5}$ on cardiorespiratory mortality, the risks with the concentration level formed a supra-linear shape [2]. Therefore, for the regional effect variation in this study, the hypothesis that the effect was lowered in high concentrations seems more plausible, since only groups with resistance remain and detrimental effects on individuals vulnerable to $\mathrm{PM}_{2.5}$ occur in lower concentrations.

There are many other genetic and environmental factors reported to cause childhood asthma besides $\mathrm{PM}_{2.5 .}$. Another hypothesis, following hygiene theory, states that allergic reactions decrease when children are exposed to micro-organisms because immune reactions are suppressed. Since westernization is still in progress in China, the effects of $\mathrm{PM}_{2.5}$ on asthma may be small $[51,52]$. There may be an objection to this statement since the three Chinese studies included in this study were conducted in Shanghai and Hong Kong, two very westernized large cities, but the infrastructure of the residences and the lifestyles of children growing up in such regions are different from those of North America and Europe.

There are some limitations of this study. First, outpatient visits, use of inhalers, and other symptom outbreaks could all be considered health effects and consequences, but we confined the results to hospital admissions and ED visits which were mainly reported in previous studies. Therefore, the pooled effect estimate reported in our study might be underestimated. But in a study that uses surveys on symptoms and use of inhalers, the period between the exposure and outbreak could be imprecise. Moreover, results from a survey could be subjec- tive. In cases of outpatient visits, we cannot exclude periodic follow-up cases. Second, we combined the RRs with the ORs because we deemed the OR to be proxy to the RR. Because of this, we may have calculated an overestimated value rather than the actual risk. However, in the case of Korea, hospitalization due to asthma among children between the ages of zero to 19 was $0.14 \%$ in 2014 [53]. The frequency of hospital admissions or ED visits due to asthma is rare so a possible bias will be negligible. Third, we could not control the innate heterogeneity of the selected studies. Components of $\mathrm{PM}_{2.5}$, ethnicities of the study population, and accessibility to health service as well as different age range, season, and adjusting variables or parameters in statistical models all probably affected the heterogeneity of the studies. However, we did not find a significant decrease of heterogeneity (Table 2). In order to obtain a more accurate pooled effect estimate, a meta-analysis should be conducted after an in-depth examination of the methods and quality of research.

The strength of this study is that we newly included seven recent studies in our meta-analysis. In addition, with a focus on children, we examined variations in effect of different possible factors, and presented the direction for future studies. In particular, we raised the need for an epidemiological study on regions besides China with high concentrations of $\mathrm{PM}_{2.5}$.

\section{CONCLUSION}

We found that in the short-term, when the concentration increased by $10 \mu \mathrm{g} / \mathrm{m}^{3}$, the risk of a child's hospital admission or ED visit increased by $4.8 \%$. If we consider the fact that air pollution affects a vast range of regions and many populations, this is not a negligible figure. A more fundamental solution is the reduction of the matter from emission sources, so we need to conduct studies on sources that emit $\mathrm{PM}_{2.5}$ and draft feasible environment-friendly policies for such emission sources.

\section{ACKNOWLEDGEMENTS}

This study was supported by the R\&D Program for Society of the National Research Foundation funded by Ministry of Science, ICT and Future Planning, Republic of Korea (grant no. 2014M3C8A5030619). 


\section{CONFLICT OF INTEREST}

The authors have no conflicts of interest associated with the material presented in this paper.

\section{ORCID}

Hyungryul Lim http://orcid.org/0000-0002-3371-0557

Ho-Jang Kwon http://orcid.org/0000-0003-3029-5674

Ji-Ae Lim http://orcid.org/0000-0003-0623-2446

Jong Hyuk Choi http://orcid.org/0000-0002-8661-493X

Mina Ha http://orcid.org/0000-0003-1011-9446

Seung-sik Hwang http://orcid.org/0000-0002-1558-7831

\section{REFERENCES}

1. Vallero DA. Fundamentals of air pollution. 5th ed. Amsterdam: Academic Press; 2014, p. 48.

2. Pope CA 3rd, Burnett RT, Krewski D, Jerrett M, Shi Y, Calle EE, et al. Cardiovascular mortality and exposure to airborne fine particulate matter and cigarette smoke: shape of the exposure-response relationship. Circulation 2009;120(11):941-948.

3. Lepeule J, Laden F, Dockery D, Schwartz J. Chronic exposure to fine particles and mortality: an extended follow-up of the Harvard Six Cities study from 1974 to 2009. Environ Health Perspect 2012;120(7):965-970.

4. Kwon HJ. Epidemiologic study of allergic diseases in Korean children. Cheongju: Korea Centers for Disease Control and Prevention; 2011, p. 23-24 (Korean).

5. Zheng XY, Ding H, Jiang LN, Chen SW, Zheng JP, Qiu M, et al. Association between air pollutants and asthma emergency room visits and hospital admissions in time series studies: a systematic review and meta-analysis. PLoS One 2015;10(9): e0138146.

6. Fan J, Li S, Fan C, Bai Z, Yang K. The impact of PM2.5 on asthma emergency department visits: a systematic review and metaanalysis. Environ Sci Pollut Res Int 2016;23(1):843-850.

7. Norris G, YoungPong SN, Koenig JQ, Larson TV, Sheppard L, Stout JW. An association between fine particles and asthma emergency department visits for children in Seattle. Environ Health Perspect 1999;107(6):489-493.

8. Lin M, Chen Y, Burnett RT, Villeneuve PJ, Krewski D. The influence of ambient coarse particulate matter on asthma hospitalization in children: case-crossover and time-series analyses. Environ Health Perspect 2002;110(6):575-581.
9. Villeneuve PJ, Chen L, Rowe BH, Coates F. Outdoor air pollution and emergency department visits for asthma among children and adults: a case-crossover study in northern Alberta, Canada. Environ Health 2007;6:40.

10. Andersen ZJ, Wahlin P, Raaschou-Nielsen O, Ketzel M, Scheike T, Loft S. Size distribution and total number concentration of ultrafine and accumulation mode particles and hospital admissions in children and the elderly in Copenhagen, Denmark. Occup Environ Med 2008;65(7):458-466.

11. Halonen J, Lanki T, Yli-Tuomi T, Kulmala M, Tiittanen P, Pekkanen J. Urban air pollution, and asthma and COPD hospital emergency room visits. Thorax 2008;63(7):635-641.

12. Tecer LH, Alagha O, Karaca F, Tuncel G, Eldes N. Particulate matter (PM(2.5), PM(10-2.5), and PM(10)) and children's hospital admissions for asthma and respiratory diseases: a bidirectional case-crossover study. J Toxicol Environ Health $A$ 2008;71(8):512-520.

13. Halonen Jl, Lanki T, Tiittanen P, Niemi JV, Loh M, Pekkanen J. Ozone and cause-specific cardiorespiratory morbidity and mortality. J Epidemiol Community Health 2010;64(9):814-820.

14. Silverman RA, Ito K. Age-related association of fine particles and ozone with severe acute asthma in New York City. J Allergy Clin Immunol 2010;125(2):367-373.

15. Strickland MJ, Darrow LA, Klein M, Flanders WD, Sarnat JA, Waller LA, et al. Short-term associations between ambient air pollutants and pediatric asthma emergency department visits. Am J Respir Crit Care Med 2010;182(3):307-316.

16. Li S, Batterman S, Wasilevich E, Wahl R, Wirth J, Su FC, et al. Association of daily asthma emergency department visits and hospital admissions with ambient air pollutants among the pediatric Medicaid population in Detroit: time-series and time-stratified case-crossover analyses with threshold effects. Environ Res 2011;111(8):1137-1147.

17. Glad JA, Brink LL, Talbott EO, Lee PC, Xu X, Saul M, et al. The relationship of ambient ozone and $\mathrm{PM}(2.5)$ levels and asthma emergency department visits: possible influence of gender and ethnicity. Arch Environ Occup Health 2012;67(2):103-108.

18. Iskandar A, Andersen ZJ, Bønnelykke K, Ellermann T, Andersen KK, Bisgaard H. Coarse and fine particles but not ultrafine particles in urban air trigger hospital admission for asthma in children. Thorax 2012;67(3):252-257.

19. Winquist A, Klein M, Tolbert P, Flanders WD, Hess J, Sarnat SE. Comparison of emergency department and hospital admissions data for air pollution time-series studies. Environ Health 2012;11:70. 
20. Delfino RJ, Wu J, Tjoa T, Gullesserian SK, Nickerson B, Gillen DL. Asthma morbidity and ambient air pollution: effect modification by residential traffic-related air pollution. Epidemiology 2014;25(1):48-57.

21. Gleason JA, Bielory L, Fagliano JA. Associations between ozone, PM2.5, and four pollen types on emergency department pediatric asthma events during the warm season in New Jersey: a case-crossover study. Environ Res 2014;132: 421-429.

22. Strickland MJ, Klein M, Flanders WD, Chang HH, Mulholland JA, Tolbert PE, et al. Modification of the effect of ambient air pollution on pediatric asthma emergency visits: susceptible subpopulations. Epidemiology 2014;25(6):843-850.

23. Wendt JK, Symanski E, Stock TH, Chan W, Du XL. Association of short-term increases in ambient air pollution and timing of initial asthma diagnosis among Medicaid-enrolled children in a metropolitan area. Environ Res 2014;131:50-58.

24. Byers N, Ritchey M, Vaidyanathan A, Brandt AJ, Yip F. Shortterm effects of ambient air pollutants on asthma-related emergency department visits in Indianapolis, Indiana, 20072011. J Asthma 2016;53(3):245-252.

25. Gleason JA, Fagliano JA. Associations of daily pediatric asthma emergency department visits with air pollution in Newark, $\mathrm{NJ}$ : utilizing time-series and case-crossover study designs. J Asthma 2015;52(8):815-822.

26. Strickland MJ, Hao H, Hu X, Chang HH, Darrow LA, Liu Y. Pediatric emergency visits and short-term changes in PM2.5 concentrations in the U.S. State of Georgia. Environ Health Perspect 2016;124(5):690-696.

27. Alhanti BA, Chang HH, Winquist A, Mulholland JA, Darrow LA, Sarnat SE. Ambient air pollution and emergency department visits for asthma: a multi-city assessment of effect modification by age. J Expo Sci Environ Epidemiol 2016;26(2):180-188.

28. Weichenthal SA, Lavigne E, Evans GJ, Godri Pollitt KJ, Burnett RT. PM2.5 and emergency room visits for respiratory illness: effect modification by oxidative potential. Am J Respir Crit Care Med 2016. doi: http://dx.doi.org/10.1164/rccm.20151224340 C.

29. Lee SL, Wong WH, Lau YL. Association between air pollution and asthma admission among children in Hong Kong. Clin Exp Allergy 2006;36(9):1138-1146.

30. Ko FW, Tam W, Wong TW, Lai CK, Wong GW, Leung TF, et al. Effects of air pollution on asthma hospitalization rates in different age groups in Hong Kong. Clin Exp Allergy 2007;37(9): 1312-1319.
31. Jalaludin B, Khalaj B, Sheppeard V, Morgan G. Air pollution and ED visits for asthma in Australian children: a case-crossover analysis. Int Arch Occup Environ Health 2008;81(8):967974.

32. Hua J, Yin Y, Peng L, Du L, Geng F, Zhu L. Acute effects of black carbon and PM2.5 on children asthma admissions: a time-series study in a Chinese city. Sci Total Environ 2014;481:433438.

33. DerSimonian R, Laird N. Meta-analysis in clinical trials. Control Clin Trials 1986;7(3):177-188.

34. Kim SY, Park JE, Seo HJ, Lee YJ, Jang BH, Son HJ, et al. NECA's guidance for undertaking systematic reviews and meta-analyses for intervention. Seoul: National Evidence-based Healthcare Collaborating Agency; 2011, p. 141-142 (Korean).

35. Anderson HR, Atkinson RW, Peacock JL, Marston L, Konstantinou K. Meta-analysis of time-series studies and panel studies of particulate matter (PM) and ozone (03): report of a WHO task group. Copenhagen: WHO Regional Office for Europe; 2004, p. 8.

36. Ruana Y, Liangb R, Liana H, Zhaoa X, Liua X, Fan Z. Endothelial function and short-term exposure to particulate matter: a systematic review and meta-analysis. J Environ Anal Chem 2015; 2(5):159.

37. Egger M, Davey Smith G, Schneider M, Minder C. Bias in metaanalysis detected by a simple, graphical test. BMJ 1997;315 (7109):629-634.

38. World Health Organization Regional Office for Europe. Effects of air pollution on children's health and development: a review of the evidence. Copenhagen: World Health Organization Regional Office for Europe; 2005, p. 12.

39. Gavett $\mathrm{SH}$, Koren HS. The role of particulate matter in exacerbation of atopic asthma. Int Arch Allergy Immunol 2001;124 (1-3):109-112.

40. Salam MT, Islam T, Gauderman WJ, Gilliland FD. Roles of arginase variants, atopy, and ozone in childhood asthma. J Allergy Clin Immunol 2009;123(3):596-602.

41. North ML, Khanna N, Marsden PA, Grasemann H, Scott JA. Functionally important role for arginase 1 in the airway hyperresponsiveness of asthma. Am J Physiol Lung Cell Mol Physiol 2009;296(6):L911-L920.

42. North ML, Amatullah H, Khanna N, Urch B, Grasemann H, Silverman $\mathrm{F}$, et al. Augmentation of arginase 1 expression by exposure to air pollution exacerbates the airways hyperresponsiveness in murine models of asthma. Respir Res 2011;12:19.

43. Li H, Romieu I, Sienra-Monge JJ, Ramirez-Aguilar M, Estela Del 
Rio-Navarro B, Kistner EO, et al. Genetic polymorphisms in arginase I and II and childhood asthma and atopy. J Allergy Clin Immunol 2006;117(1):119-126.

44. Sarnat SE, Coull BA, Schwartz J, Gold DR, Suh HH. Factors affecting the association between ambient concentrations and personal exposures to particles and gases. Environ Health Perspect 2006;114(5):649-654.

45. Lee PK, Brook JR, Dabek-Zlotorzynska E, Mabury SA. Identification of the major sources contributing to PM2.5 observed in Toronto. Environ Sci Technol 2003;37(21):4831-4840.

46. Perrone MG, Gualtieri M, Ferrero L, Lo Porto C, Udisti R, Bolzacchini $\mathrm{E}$, et al. Seasonal variations in chemical composition and in vitro biological effects of fine PM from Milan. Chemosphere 2010;78(11):1368-1377.

47. Li X, Wang Y, Guo X, Wang Y. Seasonal variation and source apportionment of organic and inorganic compounds in PM2.5 and PM10 particulates in Beijing, China. J Environ Sci (China) 2013;25(4):741-750.

48. Pui DY, Chen SC, Zuo Z. PM2.5 in China: measurements, sourc- es, visibility and health effects, and mitigation. Particuology 2014;13:1-26.

49. Lu F, Xu D, Cheng Y, Dong S, Guo C, Jiang X, et al. Systematic review and meta-analysis of the adverse health effects of ambient PM2.5 and PM10 pollution in the Chinese population. Environ Res 2015;136:196-204.

50. Franklin M, Zeka A, Schwartz J. Association between PM2.5 and all-cause and specific-cause mortality in 27 US communities. J Expo Sci Environ Epidemiol 2007;17(3):279-287.

51. Wong GW, Chow CM. Childhood asthma epidemiology: insights from comparative studies of rural and urban populations. Pediatr Pulmonol 2008;43(2):107-116.

52. Schröder PC, Li J, Wong GW, Schaub B. The rural-urban enigma of allergy: what can we learn from studies around the world? Pediatr Allergy Immunol 2015;26(2):95-102.

53. Seong SC, Son MS. National health insurance statistical yearbook 2014. Seoul: Korean Health Insurance Review \& Assessment Service; 2015, p. 470-473 (Korean). 